\title{
Determinación del efecto diurético del isaño (Tropaeolum tuberosum) y cola de caballo (Equisetum arvense) en ratones
}

\section{Determination of the diuretic effect of isaño (Tropaeolum tuberosum) and cola de caballo (Equisetum arvense) in mice}

\author{
Mabel Castro Rua ${ }^{1}$, Evelyn Gutiérrez Patzi ${ }^{2}$, Gabriela Pacheco Felipes ${ }^{3}$, Elena Tola Guarachi ${ }^{4}$, \\ Ana Callisaya Mamani ${ }^{5}$, Mónica Flores Quispe ${ }^{6}$, Helen Gonzales Beltrán ${ }^{7}$, André Villca \\ Condori $^{8}$, Luz Apaza Chambi ${ }^{9}$, PhD Evangelina Terán Ventura ${ }^{10}$
}

\section{RESUMEN}

El isaño y la cola de caballo son utilizados en Bolivia por su uso tradicional como diurético, pero no se tienen estudios farmacológicos que confirmen este efecto. Objetivo: determinar el efecto diurético del extracto acuoso de isaño y cola de caballo. Metodología: se utilizaron ratones macho, que se dividieron en cuatro grupos, un control positivo, negativo y dos grupos de dosis (D1 y D2) del extracto. Ambas plantas secas se fraccionaron para la preparación del extracto acuoso, con el que se realizó el tamizaje fitoquímico preliminar, y para determinar el efecto diurético se realizó la técnica descrita por Lipschitz. Resultados: La marcha fitoquímica reveló la presencia de flavonoides para el extracto acuoso de Cola de caballo. Y el extracto acuoso de Isaño mostró la presencia de taninos, antocianinas y flavonoides. El mayor volumen de orina recolectada fue para el control positivo, y el menor volumen fue para el control negativo. Los volúmenes de orina del extracto estudiado con respecto al control negativo y positivo estadísticamente no son significativos, pero el valor del volumen de orina de la dosis mayor se acerca más al valor del control positivo. Los resultados de electrolitos mostraron una disminución en la excreción de $\mathrm{Na}+, \mathrm{K}+$ y $\mathrm{Cl}$ - en orina de los ratones problema con respecto al grupo control negativo y control positivo, excepto el $\mathrm{K}+$ mostró valores algo elevados con respecto al control positivo. Conclusión: Los resultados confirman un posible efecto diurético del isaño y cola de caballo

Palabras clave: Equisetum arvense, Tropaeolum tuberosum, efecto diurético, flavonoides, electrolitos, ratones.

\footnotetext{
${ }^{1}$ Universidad Mayor de San Andrés, La Paz, Bolivia. Orcid ID: 0000-0003-4739-2227

${ }^{2}$ Universidad Mayor de San Andrés, La Paz, Bolivia. Orcid ID: 0000-0003-4606-8142

${ }^{3}$ Universidad Mayor de San Andrés, La Paz, Bolivia. Orcid ID: 0000-0003-4580-9885

${ }^{4}$ Universidad Mayor de San Andrés, La Paz, Bolivia. Orcid ID: 0000-0002-4917-5237

${ }^{5}$ Universidad Mayor de San Andrés, La Paz, Bolivia. Orcid ID: 0000-0002-3089-3837

${ }^{6}$ Universidad Mayor de San Andrés, La Paz, Bolivia. Orcid ID: 0000-0002-4113-6786

${ }^{7}$ Universidad Mayor de San Andrés, La Paz, Bolivia. Orcid ID: 0000-0003-4190-4965

${ }^{8}$ Universidad Mayor de San Andrés, La Paz, Bolivia. Orcid ID: 0000-0001-8716-1293

${ }^{9}$ Universidad Mayor de San Andrés, La Paz, Bolivia. Orcid ID: 0000-0002-6865-4022

${ }^{10}$ Universidad Mayor de San Andrés, La Paz, Bolivia.

Orcid ID: 0000-0002-6628-6270
} 


\begin{abstract}
Isaño and cola de caballo are used in Bolivia for their traditional use as a diuretic, but there are no pharmacological studies that confirm this effect. Objective: to determine the diuretic effect of the aqueous extract of isaño and cola de caballo. Methodology: male mice were used, which were divided into four groups, a positive and negative control and two dose groups (D1 and D2) of the extract. Both dried plants were fractionated for the preparation of the aqueous extract, with which the preliminary phytochemical screening was carried out, and the technique described by Lipschitz was carried out to determine the diuretic effect. Results: The phytochemical analysis revealed the presence of flavonoids for the aqueous extract of cola de caballo. And the aqueous extract of Isaño showed the presence of tannins, anthocyanins and flavonoids. The highest volume of urine collected was for the positive control, and the lowest volume was for the negative control. The volumes of urine of the extract studied with respect to the negative and positive control are not statistically significant, but the value of the volume of urine of the higher dose is closer to the value of the positive control. The electrolyte results showed a decrease in the excretion of $\mathrm{Na}+, \mathrm{K}+$ and $\mathrm{Cl}$ - in the urine of the problem mice with respect to the negative control group and the positive control, except the $\mathrm{K}+$ showed somewhat high values with respect to the positive control. Conclusion: The results confirm a possible diuretic effect of isaño and cola de caballo
\end{abstract}

Keywords: Equisetum arvense, Tropaeolum tuberosum, diuretic effect, flavonoids, electrolytes, mice.

\section{INTRODUCCIÓN}

Los diuréticos son fármacos que estimulan la excreción renal de agua y electrólitos, como consecuencia de su acción perturbadora sobre el transporte iónico a lo largo de la nefrona (Florez y Armijo, 2013). Cualquier medicamento con acción diurética sólo debe ser tomado bajo indicación médica, debido a que cuando se usan incorrectamente pueden provocar un desequilibrio hidroelectrolítico, que son alteraciones en la cantidad de minerales importantes en la sangre, pueden surgir otros problemas como deshidratación o arritmias cardiacas e hipotensión (Florez y Armijo, 2013). Por lo que una mejor opción en lugar de un fármaco diurético podría ser la utilización de diuréticos naturales, debido a que tienen un efecto similar a los medicamentos, pero con menos riesgos para la salud.

En Bolivia se determinaron 15 categorías de uso y aplicaciones de 105 especies de plantas medicinales expendidas por vendedoras chifleras (persona que expende plantas medicinales) de La Paz y El Alto (Justo y Morales, 2015).

El Isaño es un tubérculo originario de los Andes, geográficamente el cultivo se extiende desde Colombia hasta Bolivia, el norte de Argentina y Chile (Ramallo, 2004). Es mayormente producido por comunidades indígenas de los andes, pero su mayor producción es en Perú y Bolivia, que se produce entre los 3.500 y los $4.100 \mathrm{msnm}$, también conocido como mashua en Perú y Ecuador y cubio en Colombia (Cadima, 2006).

El nombre científico del Isaño es Tropaeolum tuberosum pertenece al reino Plantae, Filo Angiospermae, Clase dicotiledoneae, Orden Brassilaceae, Género Tropaelum, Especie tuberosum, Autor epíteto específico Ruiz \& Pavón (Ruiz y Pavon, 1794).

La planta está formada de raíces, tubérculos, tallo, hojas, flores y frutos; los tubérculos tienen forma cónica, alargada y fusiforme de diferentes colores, es considerado como un alimento nutritivo y se lo utiliza en la medicina tradicional como antibiótico y para problemas renales (Aruquipa, Trigo, Bosque, Mercado, y Condori, 2017).

La Cola de caballo es una planta perenne, vivaz, que prefiere suelos húmedos y arcillosilícicos, incluso marismas. Tiene dos tipos de tallos aéreos: unos fértiles, que aparecen en primavera, y otros estériles, que se desarrollan más tarde, los tallos fértiles son rojizos y cortos, no ramificados, sin clorofila, y tienen una espiga esporangífera oblonga. Las ramas estériles aparecen en verano, pueden alcanzar hasta 50 $\mathrm{cm}$ de altura, son de color verde y tienen tallos huecos, articulados en los nudos y recorridos por 6-12 surcos no muy profundos y ramas secundarias con 4 ángulos. En los nudos se 
insertan hojas verticiladas, de tamaño reducido; las hojas forman una vaina alrededor del tallo en forma de dientes soldados con una extremidad negra (Bruneton, 1999).

El nombre científico de la Cola de caballo es Equisetum arvense, pertenece al Reino Plantae, División Sphenophyta, Orden Equisetales, Familia Equisetaceae, Género Equisetum, Especie arvense (Linneo, 1753).

Esta planta medicinal posee un uso terapéutico reportado por la medicina tradicional, para prevenir y tratar problemas de retención de líquidos, litiasis urinaria, cistitis y tiene acción diurética (Navarrete, León, Gonzales, Avilés, Salazar, Mellado, et al, 2006).

Aunque el Isaño (Tropaeolum tuberosum) y la Cola de caballo (Equisetum arvense) se utilizan en la medicina popular de nuestro país como un diurético y problemas renales, ningún estudio se ha llevado a cabo para evaluar si la mezcla de Isaño y Cola de caballo tienen el efecto diurético, es por ello que nuestro objetivo fue evaluar el efecto diurético del extracto acuoso obtenido a partir bulbo de Isaño y hojas de la Cola de caballo en ratones.

\section{METODOLOGÍA}

\section{Obtención de las plantas}

El Isaño (bulbo de la especie Tropaeolum tuberosum) y la cola de caballo (hojas de la especie Equisetum arvense) fueron obtenidos en un mercado local de plantas medicinales del centro de la ciudad de La Paz, de personas llamadas chifleras (persona que conoce los saberes ancestrales del uso de plantas medicinales). La identificación de las plantas fue realizada por el Herbario Nacional de Bolivia, Facultad de Biología de la Universidad Mayor de San Andrés, con Ref.: 0045-18 para Isaño, y 0046-18 para Cola de caballo.

El material recolectado se lavó, corto, y posteriormente, se desecó por exposición en un lugar fresco y bajo sombra, durante 1 semana. Los procesos empleados para la recolección y procesamiento de la planta se realizaron de acuerdo a las recomendaciones del CYTED (Sharapin, 2000).

\section{Preparación del extracto}

Las hojas y tallos de la Cola de caballo y el tubérculo del Isaño secos se utilizaron para cada preparación del extracto se tomaron 15 g y 10 g respectivamente, y se les añadió 200 $\mathrm{ml}$ de agua destilada, realizando una decocción por 10 minutos, en una concentración de 12,5 $\%$ p/v, dejándolo macerando por 24 horas a temperatura ambiente y en ausencia de luz.

\section{Identificación Cualitativa de Metabolitos} secundarios

A partir del extracto total acuoso del Isaño y Cola de caballo se realizó el tamizaje fitoquímico preliminar para detectar la presencia de metabolitos secundarios mayoritarios, basado en el método descrito por Domínguez (Domínguez, 1973). Este tamizaje fitoquímico se realizó basado en reacciones de precipitación o coloración; que contó con pruebas para: flavonoides, mucilagos, taninos, alcaloides; y antocianinas para los extractos acuosos juntos y extractos acuosos por separado.

\section{Animales de experimentación}

Se utilizaron 28 ratones albinos macho de la cepa NIH Swiss de 25-30g de peso, de 6-8 semanas de edad, procedentes del Bioterio de la Facultad de Ciencias Farmacéuticas y Bioquímicas (FCFB) de la Universidad Mayor de San Andrés (UMSA) con certificado de calidad $\mathrm{N}^{\circ} 016$, en las siguientes condiciones: ciclo luzoscuridad de 12 horas; temperatura, $21^{\circ}-23^{\circ} \mathrm{C}$, y humedad relativa de $55 \%$. Antes de comenzar el estudio los animales fueron aclimatados en el laboratorio de farmacología (FCFB) por tres días. El proyecto fue revisado y aprobado por el Comité de Bioética de la Universidad Mayor de San Andrés CEI-CNB 0121-18.

\section{Evaluación de la actividad diurética}

La evaluación de la diuresis se adaptó de acuerdo a la técnica descrita Lipschitz (Lipschitz, Haddian, y Kerpscar, 1943) y modificada por Kau (Kau, Keddie, y Andrews, 1984). Se tomaron 28 ratones macho y se repartieron en cuatro grupos de 7 animales cada uno, grupo control negativo, control positivo, dosis 1 (D1), dosis 2 (D2).

Los tratamientos con D1 y D2 se administraron por vía oral en una concentración de 0.075\% y $0,15 \% \mathrm{p} / \mathrm{v}$ respectivamente. El grupo control 
negativo se administró agua destilada por VO (Figura 1 a), (a todos los ratones se administraron la dosis de $0,2 \mathrm{ml} / 20 \mathrm{~g}$ ), y el grupo control positivo se administró el fármaco furosemida $20 \mathrm{mg} / 2 \mathrm{ml}$ por vía IP a la dosis de $0,1 \mathrm{ml} / 20 \mathrm{~g}$ de peso del ratón.

\section{Evaluación de la actividad saliuretica}

La orina se recolectó durante 5 horas de los ratones en jaulas metabólicas individuales elaboradas artesanalmente (Figura 1 b) a una temperatura ambiente de $21^{\circ} \mathrm{C}$. Luego de las 5 horas, se realizó la medida de la orina colectada, para finalmente analizar las concentraciones de electrolitos como $\mathrm{Na}+, \mathrm{K}+, \mathrm{Cl}-\mathrm{y} \mathrm{Ac}$. Úrico, en la orina recolectada; la determinación se realizó con la técnica de ion selectivo utilizando un analizador de electrolitos modelo Stat Fax 4555.

Figura

1 a. Administración vía oral en los ratones.

1 b. Cajas metabólicas realizadas artesanalmente para colectar la orina de los ratones.
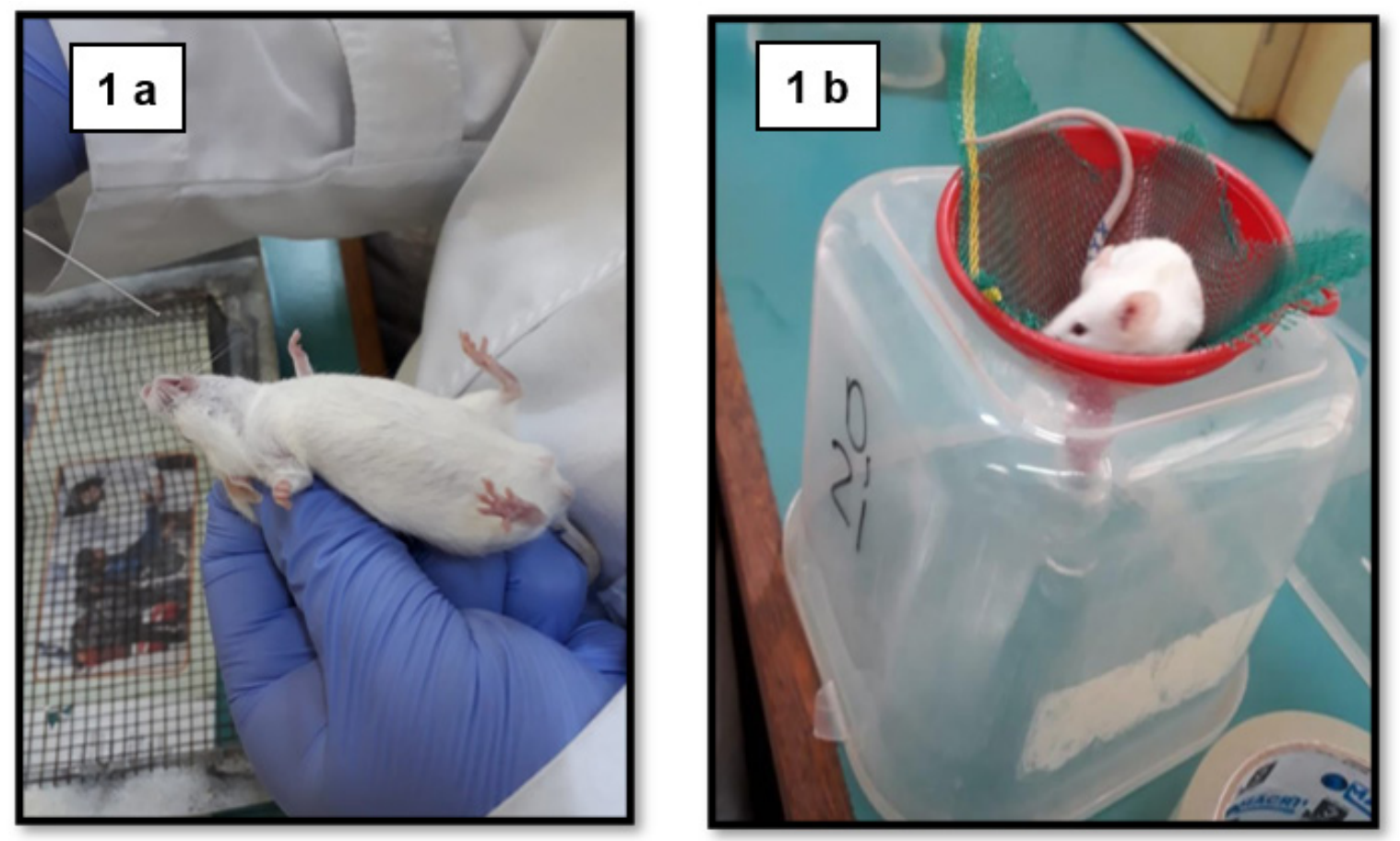

La acción diurética (a) y el índice diurético (b) se calcularon con las fórmulas:

a) Acción diurética $(A D)=$ Excreción urinaria grupo problema

Excreción urinaria grupo control negativo

b) Índice diurético (ID)= Acción diurética grupo problema

Acción diurética grupo control positivo

Ambos valores fueron calculados para todos los grupos utilizando el promedio de la cantidad de orina colectada de 5 horas en los ratones. El índice diurético obtenido fue considerado bueno si el resultado fue > 1,5; moderado si el resultado fue entre 1-1,5; bajo si el resultado estuvo entre 0,72-0,99; y nulo si el resultado estuvo por debajo de 0,72 (Sarfaraz, y Najam, 2018) y (Asif, Jabeen, Atif, Malik, y Abdul, 2014).

Utilizando los datos obtenidos de los promedios de los valores de electrolitos de la orina de los ratones, fue calculado el índice saliurético (Compaore, Lamien, Mogosan, Lamien, Kiendrebeogo, Vostinaru, et al. 2011) individualmente para $\mathrm{Na}+\mathrm{K}+\mathrm{y} \mathrm{Cl}$ - en los grupos problema entre el grupo control negativo, como se muestra en la formula (c): 
c) Índice saliurético (IS) $=$ Niveles de $\mathrm{Na}+, \mathrm{K}+, \mathrm{Cl}$ - en orina del grupo problema Niveles de $\mathrm{Na}+, \mathrm{K}+, \mathrm{Cl}$ - en orina del grupo control negativo

Utilizando los datos obtenidos de los promedios de los valores de electrolitos de la orina de los ratones, se calculó el índice natriurético con la siguiente fórmula (d):

d) Índice natriurético $(\mathrm{IN})=$ Nivel de $\mathrm{Na}+$ en la orina grupo problema Nivel de K+ en la orina grupo problema

Si el ratio de $\mathrm{Na}+/ \mathrm{K}+$ obtenido es $>$ a 1 , indica un índice natriurético satisfactorio, si es $>$ a 2 indica que es favorable para la excreción de $\mathrm{Na}+$ sin excesiva eliminación de $\mathrm{K}+$, pero si es $>10$ indica un favorable efecto ahorrador de $\mathrm{K}+\mathrm{Y}$ el índice de la inhibición de la anhidrasa carbónica (CAI) (Compaore, Lamien, Mogosan, Lamien, Kiendrebeogo, Vostinaru, et al. 2011), (Kebamo, Makonnen, Debella, y Geleta, 2015), (Deraniyagala, Ratnasooriya, y Wijetunge, 2013), se calculó con la siguiente fórmula (e):

e) Índice CAI = Nivel de Cl- en la orina grupo problema Suma de los niveles de $\mathrm{Na}++\mathrm{K}+$ en la orina grupo problema

Donde, si el valor del ratio de $\mathrm{Cl} / \mathrm{Na}++\mathrm{K}+$ esta entre $0,8-1$ se excluye actividad $\mathrm{CAl}$, pero si está por debajo de 0,8 se considera que tiene un fuerte índice CAI (Lacorte, Ang, Ferrer, Lorenzo, Oandasan, Santos, et al., 2018).

\section{Análisis estadístico}

Los resultados obtenidos fueron analizados mediante el test de ONE WAY ANOVA y el post-test Bonferroni, considerando valores significativos cuando $\mathrm{P}<0,05$ con el software Graphpad $®$ Prism 4.

\section{RESULTADOS}

\section{Identificación Cualitativa de Metabolitos secundarios}

Cola de caballo, muestran la presencia de taninos, flavonoides y antocianinas. Los resultados del extracto acuoso de Isaño y Cola de caballo eran diferentes según la bibliografía, por lo que se decidió hacer el estudio Fitoquímico de extracto acuoso de Isaño y Cola de caballo por separado. El extracto acuoso de cola de caballo muestra la presencia de flavonoides, el extracto acuoso de Isaño revela la presencia de taninos, flavonoides y antocianinas (Tabla 1). 
Tabla 1

Marcha fitoquímica pre-liminar del extracto acuoso de Isaño y Cola de caballo.

\begin{tabular}{llll} 
PRUEBA & $\begin{array}{l}\text { Extracto acuoso } \\
\text { de Isaño y Cola de } \\
\text { caballo }\end{array}$ & $\begin{array}{l}\text { Extracto acuoso } \\
\text { de cola de } \\
\text { caballo }\end{array}$ & $\begin{array}{l}\text { Extracto } \\
\text { acuoso de } \\
\text { Isaño }\end{array}$ \\
\hline Taninos con cloruro ferrico & + & - & + \\
Taninos con acetato de plomo 5\% & - & - & - \\
Alcaloides con el rvo. de draguendorff & - & - & - \\
Flavonoides. prueba de shinoda & + & + & + \\
Mucilagos (flavonoides + ) con alcohol $96^{\circ}$ & - & - & - \\
Antocianinas con $\mathrm{HCl} 5 \%$ y con $\mathrm{NAOH} 0,5 \mathrm{~N}$ & + & - & + \\
\hline
\end{tabular}

\section{Evaluación de la actividad diurética}

En la Figura 2 se muestran los valores de orina excretada en 5 horas, donde se puede observar un mayor promedio del volumen excretado que corresponde al control positivo $1,3 \mathrm{ml}$ utilizando la furosemida; y el menor promedio del volumen excretado registra el control negativo $0,5 \mathrm{ml}$, promedios de los volúmenes cuantitativamente importantes se registraron a D1 y D2 (1 ml y 1,14 ml respectivamente). Los valores encontrados muestran diferencia estadística significativa entre los volúmenes de orina excretados en el ensayo ANOVA $(P=0,015)$; la diferencia de volumen excretado de orina del control negativo es significativa $(P=0,05)$ con respecto al control positivo. Sin embargo, la diferencia de $D 1$ y D2 con respecto al control negativo no es significativa, pero el valor del volumen de orina de la D2 se acerca más al valor del control positivo.

La acción diurética fue mayor para la $\mathrm{D} 2$, el índice diurético según bibliografía citada fue bajo en ambas dosis, porque el rango fue entre $0,72-0,99$, según bibliografía reportada (Tabla 2 ).

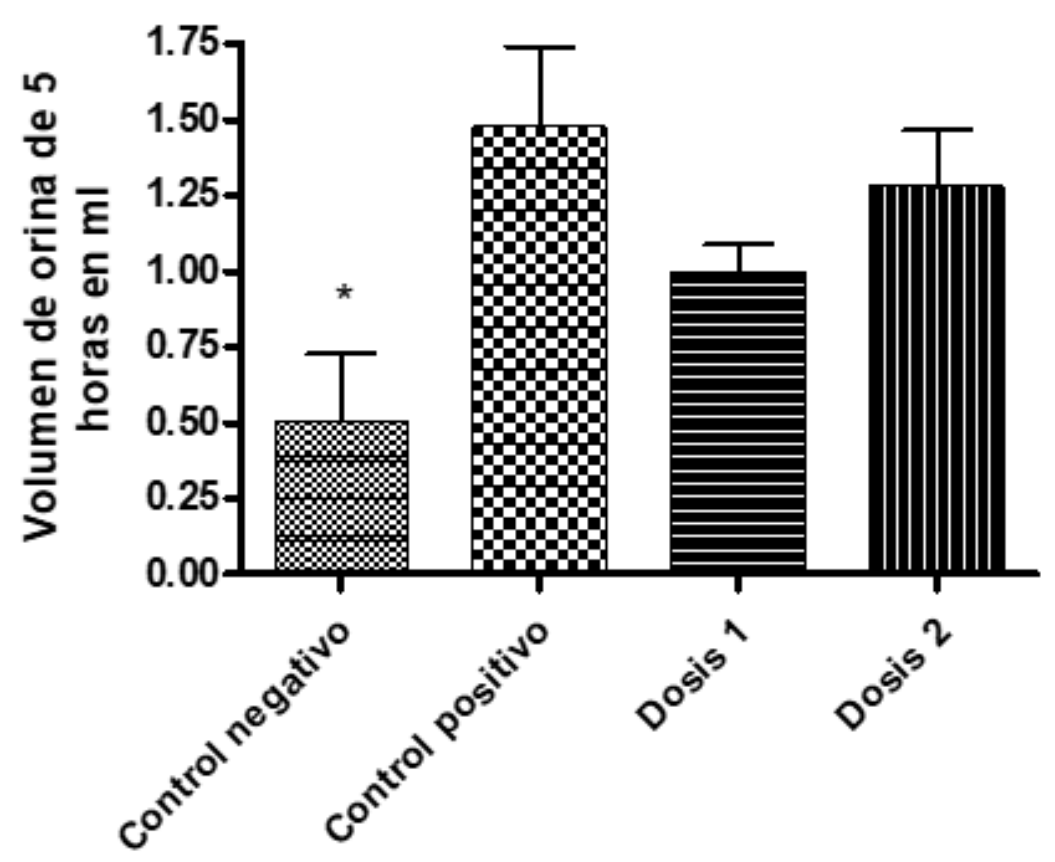

Figura 2

Efecto diurético del extracto acuoso del Isaño y Cola de caballo versus el volumen de orina excretado en 5 horas. ANOVA $P=0,015 . C-$ vs. $C+P=0,02$ * 
Tabla 2

Índice diurético y acción diurética del extracto acuoso de Isaño y Cola de caballo después de 5 horas de tratamiento.

\begin{tabular}{lll} 
Pos-tratamiento a las $\mathbf{5}$ horas & \\
Dosis & Acción diurética & Índice diurético \\
D1 & 1,97 & 0,75 \\
D2 & 2,24 & 0,86 \\
\hline
\end{tabular}

\section{Contenido de electrolitos en la orina}

En la excreción de electrolitos en la orina de los animales de experimentación después de las 5 horas de la administración del extracto de Isaño y Cola de caballo (Tabla 3 ) observamos un menor valor significativo del promedio de la excreción del electrolito $\mathrm{Na}+$ en la D1 y D2 $(73,13 \mathrm{mEq} / \mathrm{l}$ y $64,72 \mathrm{mEq} / \mathrm{l}$ respectivamente) con respecto al control positivo $(123,69 \mathrm{mEq} / \mathrm{l})$. En el análisis del electrolito $\mathrm{K}+\mathrm{se}$ observa un valor significativo del promedio de la excreción correspondiente a la administración de D2 $(92,6 \mathrm{mEq} / \mathrm{l})$ con respecto al control positivo $(41,29 \mathrm{mEq} / \mathrm{l})$. El valor de excreción de electrolitos $\mathrm{Cl}$ - nos indica una diferencia significativa correspondiente a la administración de D1 y D2 (12,12 mEq/l y 31,64 $\mathrm{mEq} / \mathrm{l}$ respectivamente) con respecto al control positivo $(162,44 \mathrm{mEq} / \mathrm{l})$. No se registraron resultados significativos en la excreción correspondiente al ácido úrico.

En conjunto se observa una disminución en la excreción de los iones $\mathrm{Na}+, \mathrm{K}+$ y $\mathrm{Cl}$ - y Ácido úrico en la orina de ratones tratados con respecto al grupo control positivo.

Tabla 3

Efecto de la administración del extracto acuoso de Isaño y Cola de caballo en la excreción de electrolitos en la orina colectada después de 5 horas.

\begin{tabular}{lllll} 
Tratamiento & \multicolumn{2}{l}{ Valor de electrolitos en orina en $\mathrm{mEq} / \mathrm{l}$} & \\
& $\mathrm{Na}^{+}$ & $\mathrm{K}^{+}$ & $\mathrm{Cl}^{-}$ & Ac. úrico \\
\hline Control negativo & $84,57+/-30,70$ & $41,29+/-2,98$ & $91,64+/-54,54$ & $0,59+/-0,63$ \\
Control positivo & $123,69+/-17,15$ & $100,71+/-31,17$ & $162,44+/-54,00$ & $0,47+/-0,29$ \\
Dosis 1 & $73,13+/-14,86^{*}$ & $70,5+/-27,54$ & $12,12+/-8,78^{* *}$ & $0,42+/-0,74$ \\
Dosis 2 & $64,72+/-9,87^{* *}$ & $92,6+/-34,91^{*}$ & $31,64+/-29,566^{* *}$ & $0,2+/-0,31$ \\
\hline
\end{tabular}

Los datos se presentan como el promedio +/- error estándar de la media. ANOVA P=0,0002 Na+: Dosis 1 vs. C positivo *; Dosis 2 vs. $\mathrm{C}$ positivo **; ANOVA P $=0,002 \mathrm{K+}$ : C positivo vs. Dosis 2 *; ANOVA P=0,0001 Cl- : C negativo vs. D1*, C positivo vs. D1 y D2***.

${ }^{*} \mathrm{P}<0.05 ;{ }^{* *} \mathrm{P}<0.001, \mathrm{P}<0,0001$.

\section{Evaluación de la actividad saliurética}

Los resultados del índice saliurético de $\mathrm{K}+, \mathrm{Cl}$ - fueron bajos en la $\mathrm{D} 1$ ( 0,7 y 0,14 respectivamente) con relación a la D2, excepto para el ión Na+ que fue más alto en la D1 $(0,86)$ con respecto a D2 $(0,76)$. Los resultados para la D1 muestran un índice natriurético satisfactorio $(1,02)>$ a 1 . Y los resultados para la D1 y D2 indican tener un fuerte incide CAI (0,084 y 0,2 respectivamente) (Tabla 4). 
Tabla 4

Efecto de la administración del extracto acuoso de Isaño y Cola de caballo en la excreción de electrolitos en la orina colectada después de 5 horas. Índice Saliurético, Natriurético y CAI.

\begin{tabular}{|c|c|c|c|c|c|}
\hline Dosis & $\begin{array}{l}\text { Índice } \\
\text { electro } \\
\text { gativo } \\
\mathrm{Na}^{+}\end{array}$ & $\begin{array}{l}\text { ureticc } \\
\text { proble } \\
\mathbf{K}^{+}\end{array}$ & $\begin{array}{l}\text { electrolito control ne- } \\
\mathrm{Cl}^{-}\end{array}$ & $\begin{array}{l}\text { Índice natriuretico } \\
\mathrm{Na}^{+} / \mathrm{K}^{+}\end{array}$ & $\begin{array}{l}\text { Índice CAI } \\
\mathrm{Cl}^{-} / \mathrm{Na}^{+}+\mathrm{K}^{+}\end{array}$ \\
\hline Dosis 1 & 0,86 & 0,7 & 0,13 & 1,02 & 0,084 \\
\hline Dosis 2 & 0,76 & 0,92 & 0,34 & 0,7 & 0,2 \\
\hline
\end{tabular}

\section{DISCUSIÓN}

La actividad diurética puede ser muy útil en una serie de afecciones como hipertensión arterial, hipercalciuria y cirrosis hepática (Nedi, Mekonnen, y Urga, 2004). Y dado que los diuréticos se emplean clínicamente en el tratamiento del edema y la hipertensión arterial, sería muy importante demostrar la eficacia de plantas medicinales sin la alteración de electrolitos. Por lo tanto, se presume que podría ser ventajoso realizar ensayos pre-clínicos en animales de laboratorio con varios extractos de plantas medicinales como agentes de detección de posible actividad diurética, y que no afecte al equilibrio de los electrolitos como el $\mathrm{Na}+, \mathrm{K}+$ y Cl-.

El tubérculo Isaño, desde tiempos remotos es utilizado por la Medicina Tradicional para tratamientos antiinflamatorios de la próstata, ya que tiene la propiedad de "reprimir el apetito venéreo" (propiedad anafrodisiaca) (Soukup, 1987). Y tiene el efecto de disminuir la cantidad de espermatozoides (Valenzuela, Góngora, Dueñas, Velázquez, Ramos, y Valenzuela, 2019). Es así, que realizamos los ensayos de caracterización cualitativa con el extracto acuoso de Isaño, que mostraron la presencia de flavonoides, y está en desacuerdo con los resultados preliminares de Aillón (Aillón, 2014), que indica que el Isaño no tiene Flavonoides. Pero está de acuerdo con Córdova e Inga donde indican sus resultados preliminares que, entre los metabolitos secundarios presentes del tubérculo de Tropaeolum tuberosum (Mashua negra) se encontraron los flavonoides (Cordova, e Inga, 2019).

Equisetum arvense se utiliza para aumentar la cantidad de orina consiguiendo limpiar el tracto urinario y ayudar en trastornos urinarios leves y para fortalecer el cabello y las uñas quebradizas. Basado exclusivamente en su uso tradicional (Vademecum, 2016).
Así también realizamos los ensayos de caracterización cualitativa con el extracto acuoso de Cola de caballo que indicaron la presencia de flavonoides, lo cual está en acuerdo con Bruneton y Lopez (Bruneton, 1999), (Lopez, 2020).

Entonces gracias a la presencia de Flavonoides en el extracto acuoso preparado con Isaño y Cola de caballo, podría atribuirse parte de la responsabilidad de su efecto diurético (Lopez, 2020).

El efecto diurético del extracto de Isaño y Cola de caballo obtuvo un comportamiento dosisefecto dependiente, es decir a mayor dosis mayor efecto diurético, por tanto el extracto a la D2 podría presentar un evidente efecto diurético. Los volúmenes de excreción urinaria por efecto del tratamiento con el extracto de Isaño y Cola de caballo fueron similares al control positivo (furosemida). Al comparar los resultados obtenidos de esta investigación con otro estudio del Isaño donde los autores reportan en sus resultados preliminares, que el extracto de Isaño a la dosis de $500 \mathrm{mg} / \mathrm{kg}$ presenta mayor actividad diurética en ratas albinas (Cordova, e Inga, 2019). Otro estudio reporta que la Cola de caballo produce también un efecto diurético en personas voluntarias sanas, y concluyen indicando que el efecto diurético de la Cola de caballo fue mayor que el control negativo y equivalente a la Hydroclorotiazida (control positivo) sin causar cambios significantes en la eliminación de electrolitos (Carneiro, Freire, de Deus Honorio, Zoghaib, Fernandes, Manrique, et al., 2014). Por tanto, nuestros resultados revalidarían un efecto diurético del Isaño y la Cola de caballo, la cual podría ser un importante coadyuvante en las cistitis al provocar una diuresis acuosa (acuaresis) sin modificar el equilibrio electrolítico, como indica Bruneton y López (Bruneton, 1999), (Lopez, 2020). Es importante resaltar que, nuestros resultados 
serían los primeros en mostrar un efecto diurético de la mezcla del extracto acuoso de Isaño y Cola de caballo.

Lo valores de las concentraciones de $\mathrm{Na}+, \mathrm{K}+, \mathrm{Cl}-$ y Ac. Úrico en orina de los ratones fueron bajos en ambas dosis del extracto acuoso de Isaño y Cola de caballo. Se observó una disminución de los valores de las concentraciones de $\mathrm{Na}+, \mathrm{K}+$, $\mathrm{Cl}$ y Ac. Úrico, con respecto al control positivo, hecho que podría deberse a que el extracto provocaría una diuresis acuosa sin modificar el equilibrio electrolítico (Lopez, 2020), (Valliere, 1981).

El índice diurético que fue bajo para ambas dosis del extracto en estudio; esto podría deberse a las concentraciones de las dosis D1 y D2 que no alcanzaron sus dosis recomendables para producir un efecto diurético.

El índice saliurétrico también fue bajo para D1 y D2 del extracto en estudio; esto podría deberse a la baja concentración en la excreción de los iones $\mathrm{Na}+, \mathrm{K}+\mathrm{y} \mathrm{Cl}-$.

El cociente de $\mathrm{Na}+/ \mathrm{K}+$ fue calculado como indicador de la actividad natriurética (índice natriurético). El cociente $\mathrm{Na}+/ \mathrm{K}+$ serviría como indicador para comparar el efecto de los diferentes diuréticos, así la furosemida (diurético de elevada eficacia) tiene un valor aproximadamente igual a 1 , debido a la alta eliminación de ambos iones en orina. Para las tiazidas este cociente es menor que 1 ya que aumenta la concentración urinaria de potasio, alterando la relación $\mathrm{Na}+/ \mathrm{K}+$. En el caso de los ahorradores de $\mathrm{K}+$ el cociente es mayor que 1 ya que las concentraciones de este ión en orina se encuentran disminuidas. Nuestros resultados muestran que la relación $\mathrm{Na}+/ \mathrm{K}+$ es menor que 1 en la Dosis 2 del extracto, esto sugiere que el efecto diurético es similar a las tiazidas. Al contrario, la Dosis 1 , reveló una relación $\mathrm{Na}+/ \mathrm{K}+$ mayor que 1 , que demostraría que el extracto estaría actuando como un diurético ahorrador de potasio como la espironolactona (Intersimone, Daud, Sánchez, 2005).

La relación $\mathrm{Cl}-/ \mathrm{Na}++\mathrm{K}+$ (índice $\mathrm{CAl}$ ) muestra el grado del efecto inhibidor de la anhidrasa carbónica. La inhibición de la anhidrasa carbónica se puede excluir en proporciones entre 0,8 y 1,0 y menor que estas proporciones es un indicativo de una fuerte inhibición de la anhidrasa carbónica (Lacorte, Ang, Ferrer,
Lorenzo, Oandasan, Santos, et al., 2018). La inhibición de la anhidrasa carbónica en el cuerpo provoca diuresis o aumento de la producción de orina. El extracto en estudio con ambas dosis D1 y D2 representa un fuerte indicativo de inhibición de la anhidrasa carbónica. Por tanto, es plausible suponer que uno de los posibles mecanismos de acción de estos extractos podría ser la inhibición de la anhidrasa carbónica, también es razonable sugerir que los constituyentes presentes en el Isaño y Cola de caballo parecen tener diferentes mecanismos de acción diuréticos con ambas dosis.

Todos estos elementos nos permiten concluir que el extracto acuoso obtenido del tubérculo Isaño (Tropaeolum tuberosum) y la Cola de caballo (Equisetum arvense), posterior administración en los ratones, demuestran un posible efecto diurético, sin modificar el equilibrio hidroelectrolítico, lo cual podría aprovecharse para el tratamiento de la hipertensión arterial, con menos riesgos para la salud.

Por otro lado, se necesitaría realizar otras investigaciones para encontrar el mecanismo de acción exacto del efecto diurético, separación del metabolito secundario responsable de este efecto diurético, evaluación de la eficacia a largo plazo y el perfil de seguridad, y otros posibles efectos farmacológicos.

\section{Declaración de financiamiento y de conflictos de interés}

El estudio fue financiado por los autores, quienes declaran no tener algún tipo de conflicto de interés en la investigación realizada.

\section{Correspondencia}

\section{Evangelina Terán Ventura}

Correo electrónico:

linateve1@yahoo.es 


\section{REFERENCIAS}

Aillón C. (2014). Estudios de actividad antioxidante en fracciones provenientes de dos plantas medicinales ecuatorianas: Extractos hidroalcohólicos de Mashua Tropaeolum tuberosum (Ruiz y Pavon) Tropaeolacea y aceite esencial de Congona Peperonia Inaequalifolia Piperacea (Tesis de pre-grado para obtener el Título de Ingeniero en Biotecnología de los Recursos Naturales). Universidad Politécnica Salesiana. Quito-Ecuador. 119-120 p. Disponible en: https://dspace.ups.edu.ec/ handle/123456789/9903

Aruquipa R, Trigo R, Bosque H, Mercado G, Condori J. (2017). El Isaño (Tropaeolum tuberosum) un cultivo de consumo y medicina tradicional en Huatacana para el beneficio de la población boliviana. Revista de Investigación e Innovación Agropecuaria y Recursos Naturales. 3(2):146151. (Fecha de consulta: 15.05.2020) Disponible en http://www.scielo.org.bo/pdf/riiarn/v3n2/v3n2 a04.pdf

Asif M, Jabeen Q, Atif M, Malik A, Abdul A. (2014). Diuretic activity of Achyranthes aspera Linn crude aqueous extract in albino rats. Tropical Journal of Pharmaceutical Research. 13(12):2039-2045. https://doi.org/10.4314/tjpr.v13i12.14

Bruneton J. (1999). Pharmacognosie Phytochimie, Plantes médicinales. 3e édition. París: Tec \& Doc/ Editons médicales internationales; 1120 p.

Cadima F. (2006). Tubérculos. En: R. Moraes, B. Ollgaard, L.P. Kvist, F. Borchsenius and Balslev $\mathrm{H}$, editores. Botánica Económica de los Andes Centrales. Universidad Mayor de San Andrés, La Paz, Bolivia. 347 - 369 p.

Carneiro D, Freire R, de Deus Honorio T, Zoghaib I, Fernandes F, Manrique F. et al. (2014). Randomized, Double Blind Clinical Trial to Assess the Acute Diuretic Effect of Equisetum arvense (Cola de caballo) in Healthy Volunteers. Evid Based Complement Alternat Med. 1-8. https:// dx.doi.org/10.1155/2014/760683

Compaore M, Lamien A, Mogosan C, Lamien C, Kiendrebeogo M, Vostinaru O, et al. (2011). Antioxidant, diuretic activities and polyphenol content of Stereospermum kunthianum Cham (Bignoniaceae). Natural Product Research. 25(19):1777-1788. https://doi.org/10.1080/14786 419.2010 .488630

Cordova C, Inga J. (2019). Actividad diurética del extracto hidroalcoholico del tubérculo de Tropaeolum tuberosum (Mashua negra) en ratas albinas. (Tesis de pre-grado para optar al título de Químico Farmacéutico y Bioquímico). Universidad Inca Garcilaso de la Vega. Facultad de Ciencias Farmacéuticas y Bioquímicas. LimaPerú. 2019. 42 p. Disponible en: http://repositorio. uigv.edu.pe/handle/20.500.11818/4950

Deraniyagala S, Ratnasooriya W, Wijetunge S. (2013). Oral diuretic activity of water extract of Ricinus communis leaves in rats. International Journal of Institutional Pharmacy and Life Sciences. 3(4):1-11. (Fecha de consulta: 10.05.2020) Disponible en http://ijipls.com/uploaded/journal_ files/130804100830.pdf

Domínguez X. (1973). Métodos de investigación fitoquímica. México. Editorial Limusa; 281 p.

Florez J, Armijo J. (2013). Fármacos Diuréticos. En: Florez J., Armijo J, Mediavilla A., editores. Farmacología Humana. Tercera edición. Barcelona-España: Editorial Masson S.A. 815 p.

Intersimone N, Daud A, Sánchez A. (2005). Efecto diurético de extractos acuosos y alcohólicos de flores de Phrygilanthus acutifolius (corpo) en ratas. Rev Cubana Plant Med. 10(3):3-7. (Fecha de consulta: 10.06.2020). Disponible en http:// scielo.sld.cu/pdf/pla/v10n3-4/pla033-405.pdf

Justo M, Morales M. (2015). Plantas medicinales comercializadas por las chifleras de La Paz y El Alto (Bolivia). Ecología en Bolivia; 50(2): 66-90. (Fecha de consulta: 22.06.2020). Disponible en: http:// www.scielo.org.bo/pdf/reb/v50n2/v50n2_a02.pdf

Kau S, Keddie J, Andrews D. (1984). A method for screening diuretic agents in the rat. $J$ Pharmacol Meth. 1984;11(1):67-75. https://doi. org/10.1016/0160-5402(84)90054-8

Kebamo S, Makonnen E, Debella A, Geleta B. (2015). Evaluation of diuretic activity of different solvent fractions of methanol extract of Carissa edulis root bark in rats. Med Chem (Los Angeles). 5(11):472478. https://doi.org/10.4172/2161-0444.1000304

Lacorte L, Ang J, Ferrer D, Lorenzo S, Oandasan M, Santos S, et al. (2018). Diuretic activity of Kalumpang (Stercula foetida L.) methanolic leaf Extract in male albino Sprague Dawley rats. Asian J Biol Life Sci. 7(2):33-39. https://dx.doi. org/10.5530/ajbls.2018.7.1

Linneo C. (1753). Species Plantarum. Paris: Imprenta Laurenti Salvil.

Lipschitz W, Haddian Z, Kerpscar A. (1943). Bioassay of diuretics. J Pharm Exp Ther. 79(2):97-110.

Lopez M. (2020). Plantas Medicinales con Acción Diurética. Fitoterapia. (Fecha de consulta: 15.05.2020). Disponible en https://www.elsevier. es/es-revista-offarm-4-pdf-13761. 
Navarrete H, León B, Gonzales J, Avilés D, Salazar J, Mellado F, et al. (2006). Helechos. En: Morales R, Ollgaard B, Kvist L, Borschenius F, y Balslev $H$, editores. Botánica económica de los Andes Centrales. Universidad Nacional de San Andrés, La Paz, Bolivia. 385-411.

Nedi T, Mekonnen N, Urga K. (2004). Diuretic effect of the crude extracts of Carissa edulis in rats. J. Ethnopharmacol. 95(1):57-61. https://doi. org/10.1016/j.jep.2004.06.017

Ramallo R. (2004). Análisis Exploratorio de los ácidos grasos del Isaño (Tropaeolum tuberosum). Investigación \& Desarrollo. 1(4):69-74. (Fecha de consulta: 15.05.20). Disponible en: http://www. upb.edu/sites/default/files/8RamalloN4.pdf

Ruiz H, Pavón J. (1794). Florae Peruvianae, et Chilensis Prodromus. Madrid. https://doi. org/10.5962/bhl.title.814

Sarfaraz S, Najam R. (2018). Evaluation of diuretic and saliuretic potencial of Beta vulgaris (beet root) at different doses. Indian Journal of Pharmaceutical Education and Research. 52(2): 248-254. https:// doi.org/10.5530/ijper.52.2.28

Sharapin N. (2000). Materias primas vegetales para la industria de productos fitoterapéuticos y Fundamentos de tecnología de productos fitoterapéuticos. Colombia-Bogotá. Editorial: CYTED Convenio Andrés Bello; 17-26 p.
Soukup J. (1987). "Vocabulario de los nombres vulgares de la flora peruana". Lima: Editorial Salesiana. 7: 49-96 p.

Valenzuela C, Góngora N, Dueñas M, Velázquez L, Ramos A, Valenzuela N. (2019). Efecto de los extractos secos clorofórmico y de diclorometano de Tropaeolum tuberosum (Ruiz \& Pavón) mashua sobre los parámetros seminales y toxicidad aguda. Rev. Colomb. Cienc. Quím. Farm. 48(1), 94-111.

Vademecum. (2016). Indicaciones terapéuticas Equisetum arvense. España; (Consultado 15 de mayo de 2020). Disponible en https:// www.vademecum.es/principios-activosequisetum+arvense-c03db+m1-us

Valliere J. (1981). Etude botanique et chimique de Equisetum arvense. Recherche d'un effect diurètique (Tesis doctoral). Toulouse-Francia.

Recibido: 18/08/2021

Aceptado: 04/10/2021 